\title{
A framework for customer relationship management strategy orientation support in higher education institutions
}

Article

Accepted Version

Khashab, B., Gulliver, S. R. and Ayoubi, R. M. (2020) A framework for customer relationship management strategy orientation support in higher education institutions. Journal of Strategic Marketing, 28 (3). pp. 246-265. ISSN 1466-4488 doi: https://doi.org/10.1080/0965254X.2018.1522363 Available at https://centaur.reading.ac.uk/79214/

It is advisable to refer to the publisher's version if you intend to cite from the work. See Guidance on citing.

To link to this article DOI: http://dx.doi.org/10.1080/0965254X.2018.1522363

Publisher: Taylor \& Francis

All outputs in CentAUR are protected by Intellectual Property Rights law, including copyright law. Copyright and IPR is retained by the creators or other copyright holders. Terms and conditions for use of this material are defined in the End User Agreement.

www.reading.ac.uk/centaur 
Central Archive at the University of Reading

Reading's research outputs online 


\title{
A Framework for Customer Relationship Management Strategy Orientation Support in Higher Education Institutions
}

\begin{abstract}
A number of generic CRM implementation frameworks have been developed, yet no systematic framework has been developed to help HEIs orientate CRM strategy to align with university business strategies and stakeholder needs. This research iteratively develops the CRM Strategy Orientation Support (CRM-SOS) framework, which aims to support HEIs in orientating their strategic CRM system at the pre-implementation stage and align CRM strategy with the business strategy; thus, reducing the chance that HEIs will experience CRM implementation failure. To reach our proposed CRM-SOS framework, we employed Design Science Research (DSR) methodology steps (Vaishnavi and Kuechler 2004) by analysing UK HEIs specific CRM implementation case studies, conducting semi-structured HEIs-based interviews, followed by evaluation of the resulted framework by HEI Information Systems (IS) experts. We concluded with a new CRM-SOS framework for HEIs consisting of five stages. The framework can be used to personalise the stages until they fit the strategic outputs and match the top management KPIs. Although existing research agrees that intensive attention should be given to CRM planning, there is no consensus or developed framework, for use within HEIs, demonstrating how CRM strategy can be orientated to align with university strategies and customer needs.
\end{abstract}

Keywords: Customer Relationship Management (CRM), CRM Strategy, CRM frameworks, Higher Education, UK universities. 


\section{Introduction}

Use of CRM technology solutions is becoming a strategic must-have in HEIs. Daradoumis et al. (2010) stated that increased domain competition has forced non-profit firms, such as universities, to firstly offer a more customer-centric approach, secondly to deliver higher quality services (Neville et al. 2002), and finally consider the adoption of CRM systems (Wali and Wright 2016, Rigo et al 2016, Wali et al. 2015, Mellors-Bourne et al. 2014, Perry et al. 2011, Seeman and O'Hara 2006, Hemsley-Brown and Oplatka 2006, Neville et al. 2005). HEIs, especially those that want to compete internationally, need to restructure their organisations, adjust their business models, and modernise their processes to align with customer needs. Despite confused and often conflicting understandings within HEIs, interest in CRM has soared. Perry et al. (2011) stated that university staff should all understand and communicate using CRM. Seeman and O'Hara (2006) claimed that implementing CRM within the university improves management of customer data process, raises student-oriented focus and increases student retention, loyalty and satisfaction with the university's services. Biczysko (2010) highlighted that by conducting frequent surveys to measure the students' satisfaction and reacting immediately to their demands, student retention can be significantly improved; which is of significant financial value to management. Consequently, institutions are increasingly using CRM technology solutions to facilitate client/university interactions and enable HEI senior managers to monitor day to day operations (Rigo et al. 2016, Kumar 2010, Binsardi and Ekwulugo 2003).

To date, there has been much confusion, in both commercial and academic domains, as to exactly "what CRM includes?". Researchers view CRM as a synthesis between: philosophy and IT (Magana and Whitehead 2010); IT and strategy (Payne 2005), human, technical and business capabilities (Coltman, 2007); process, IT and people (Greenberg 2010); and business strategy, IT, and process (Buttle and Maklan 2015). There is, however, increasing evidence that CRM success can only be achieved if CRM is seen as a critical business strategy (CambraFierro et al. 2017, Buttle and Maklan 2015, Gummesson 2009, Thakur et al. 2006, Lindgreen et al. 2006, Payne and Frow 2005, Bligh and Turk 2004, Leigh and Tanner 2004, Leigh and Tanner 2004, Rigby and Ledingham 2004), and that CRM software technologies should only be implemented to facilitate that CRM strategy. Although existing research agrees that intensive attention should be given to CRM planning, there is no consensus or developed framework, for use within HEIs, demonstrating how CRM strategy can be orientated to align with university strategies and customer needs. There is, however, limited research supporting HEIs in how CRM should be strategically implemented to support alignment of CRM strategy with university activity and customer needs.

In HEIs, we see the concept of value as different from commercial businesses. HEIs are largely unable to segment 'customers' in terms of 'profit' key performance indicators, and the concept of 'valuable customer' depends significantly on the business to the business domain. HEIs are considered to be 'non-profit organisations' with a primary focus on providing high-quality education and producing knowledge - rather than profit to shareholders. Accordingly, we view the output focus and use of CRM in HEIs to be likely different from commercial business. Accordingly, this study will address this problem and develop a framework to support CRM strategy orientation in HEIs for strategic purposes. 


\section{Generic CRM Implementation Models}

Within the commercial domain, considerable literature emphasises the importance of the preimplementation phase on CRM strategy orientation. In 2001, Gartner introduced the 'Eight Building Blocks of CRM' (Kirkby 2002). The Gartner model guides CRM implementation towards success by ensuring inclusion of works, and consideration of critical success factors (Almotairi 2010). The Gartner model states that CRM goals must be specific and measurable, i.e. timely and achievable, and highlights the necessity of assessing the company's existing competencies. Gartner's framework considers the development of the CRM vision and use of internal education, yet the framework fails to consider critical success and failure factors (Almotairi 2010). Payne and Frow (2005) proposed a strategic CRM framework that emphasised the importance of strategy. Despite highlighting the importance of developing and implementing CRM strategies, Payne and Frow failed to mention how the business strategy or customer strategy could be assessed and/or analysed, and how the stakeholder requirements could be elicited and analysed. Thakur et al. (2006) considered the reasons of approaching CRM as a strategy, and defined a diverse range of critical success factors in their model, however failed to link the model to the customer's needs and/or consider the customer life cycle, and did not provide any guidelines on how strategy can be orientated. Magana and Whitehead (2010) described CRM implementation stages, and emphasised the need to consider people and management issues. They stated that an enterprise should undertake CRM implementation to meet measurable CRM shortcomings in the business process. Despite their attention to strategy, they neglected to consider CRM strategy needs in terms of the common CRM components (i.e. people, process and technology).

The Relationship Management Model (IDIC) was developed as a relationship creation model and suggests that enterprises should undertake four interrelated implementation tasks in order to create one-to-one relationships; resulting in superior customers value (Peppers and Rogers 2004). The tasks are: i) identify customer needs; ii) differentiate valuable customers; iii) interact with customers to understand customer expectations, i.e. complex desires, wants, and preferences, and their relationships with other suppliers or brands; iv) customise the offer, and communications, to ensure that the expectations of customers are met. Although the IDIC model mentions segmentation as an important part of CRM strategy, i.e. treating customers differently based on their value and needs, no discussion is given to how the value, or customer needs, is measured, and the authors do not provide any guidelines and/or detailed steps as to how CRM strategy can be orientated. They further neglected essential issues concerning: CRM strategy, consideration of Critical Success Factors (CSFs), current CRM situation analysis, how customer requirements link to the CRM solution types like collaborative and strategic CRM types, and how the CRM solution links to the customer life cycle. Alternatively, Buttle and Maklan (2015) defined five iterative high-level phases. Their model aims to minimise errors and define training needs; while maximising benefits for all stakeholders when rolling out the successful CRM. They highlighted the significance of change, project and risk management when delivering customer's needs into desired products and services, and addressed a number of drawbacks raised in other frameworks, yet did not justify the use of their criteria or define the connection to CRM components (i.e. people, technology and processes). Although CRM implementation frameworks have been developed, a number of problems were identified (see Table 1). 


\begin{tabular}{|c|c|c|c|c|c|c|c|c|c|c|c|}
\hline & 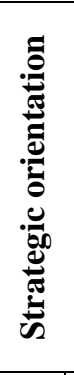 & 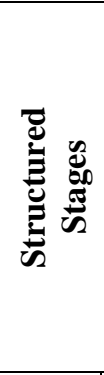 & 密 & 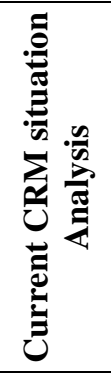 & 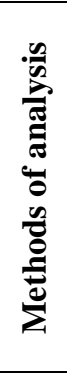 & 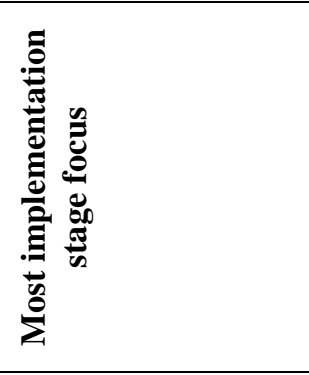 & $\begin{array}{l}\dot{\vec{\theta}} \\
\stackrel{\Xi}{0}\end{array}$ & 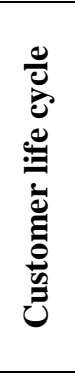 & 总 & 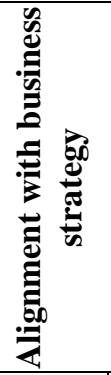 & $\underline{2}$ \\
\hline Gartner, 2001 & & & & & $\checkmark$ & Pre-implementation & & $\checkmark$ & & & $\checkmark$ \\
\hline $\begin{array}{l}\text { Payne and Frow, } \\
2005\end{array}$ & & & & & & Pre-implementation & & & & & $\checkmark$ \\
\hline $\begin{array}{l}\text { Magana and } \\
\text { Whitehead, 2010 }\end{array}$ & & & $\checkmark$ & & & Pre-implementation & & & & & \\
\hline IDIC Model, 2004 & & & $\checkmark$ & & & Pre-implementation & & & & & \\
\hline Thakur et al., 2006 & & & $\checkmark$ & & & Pre-implementation & & & & & \\
\hline $\begin{array}{l}\text { Buttle } \\
\text { Maklan, 2015 }\end{array}$ & & & $\checkmark$ & $\checkmark$ & $\checkmark$ & Pre-implementation & $\checkmark$ & $\checkmark$ & $\checkmark$ & & $\checkmark$ \\
\hline
\end{tabular}

Table 1: Comparisons of CRM implementation models

\section{Review of CRM Strategy Orientation Studies in HE}

HEIs are complex organizations, offering a wide range of services and involving a multiplicity of stakeholders; both in terms of type and number (Saiti and Prokopiadou 2008). HEIs are distinct from other types of organizations; possessing a high degree of specialization in both organizational structure and service provision (Mattheou and Saiti 2005). Unlike most companies, in HEIs, the output product is commonly the customer (Kotler and Fox 1985). Defining quality in HEIs is very difficult due to the multiplicity of stakeholders, and satisfying the conflicting needs of HEIs' customer groups and stakeholders is complex; since different groups often demand conflicting business outcomes (Lagrosen et al. 2004, Harvey and Knight 1996, Green 1994). However, universities need to address the possible effect of narrowing the scope of their CRM activity to focus directly on the customers that matter most and are likely to bring a return on investments ( $\mathrm{O}^{`}$ Regan 2010). Grant and Anderson (2002) believed that integrating CRM within processes can help universities gain a 360 view of their customers, and can aid efficiency improvements in key activities, i.e. increasing revenue through improving retention recruitment rates, reduce recruiting costs, enhanced customer service and customer satisfaction, enabling universities to concentrate on customer-centricity and quality improvements (Hanover 2010).

Due to the high level of customer interaction in HEIs, applying CRM solutions facilitates managing interactions and touch points across multiple communication channels (Lávanya 2011). Many USA HEIs have gained considerable benefits from using CRM (Seligman and Taylor 2009). For example, Seeman and O'Hara (2006) considered that the implementation of CRM at North Carolina Community College has improved management of customer data process; increased student-oriented focus; increased student retention; and a growth in student loyalty and satisfaction concerning the university's educational programs and services. Biczysko (2010) stated that DePaul University (USA) used CRM systems effectively to enhance student retention and help identify students at risk of dropping out from the university. They conducted frequent surveys via E-mail to measure students' satisfaction and reacted immediately to their demands. Consequently, student retention in this university increased by four per cent (Biczysko 2010). 
UK HEIs find themselves under increasing pressure to manage existing spending, to facilitate the extra benefits required to balance the value equation (value $=$ benefits/sacrifice) (Binsardi and Ekwulugo 2003, Grant and Anderson 2002). Kaiser et al. (1999) stated that HEIs are increasingly looking to adopt market orientation activities, to attract, interact with, retain, and serve their customers efficiently and effectively, which requires them to embrace innovative solutions if they are going to continue to build effective relationships and improve the value perception of their customers. Kumar (2010) stated that, in HEIs, this issue is compounded by institutions adopting new modes of teaching, such as e-learning, franchised and overseas degree programmes; that reduce face-to-face interaction and increase the complexity of managing the customer experience (Grant and Anderson 2002).

Conducting research on the international students' perception of UK HEIs, Binsardi and Ekwulugo (2003) concluded that the best conversion towards satisfying students' needs was achieved by managing the relationships with alumni, friends, relatives, local universities/colleges, the British Council, and media providers. Seligman and Taylor (2009) scrutinised the current and possible CRM applications in UK universities and revealed that the use of technologies was limited, and there was a dearth of management understanding of CRM solution functionality. They indicated that the administrative staff at UK universities attempt to satisfy their students and stakeholders, but current weak and/or inconsistent systems are limiting potential benefits. Using semi-structured interviews at five of the top universities in Sweden, $10 \%$ of all Swedish universities, Bagheri and Beheshti (2010) proposed a conceptual CRM model for use by Swedish universities, which can help the marketing department at the recruitment stage of the student lifecycle; yet ignores other university activity and/or other parts of the customer lifecycle. Daradoumis et al. (2010) proposed a generic CRM framework, for use by non-profit organisations, which specifically considered CRM application use in the field of e-learning monitoring system, however their framework viewed CRM as purely an application solution, rather than strategy.

Haywood et al. (2007) revealed that the use of CRM implementation within UK HEIs to support BCE (Business and Community Engagement)/ knowledge transfer activities is still under-developed and that CRM systems are not strategically considered, and therefore suffer from a poor level of CRM consolidation with other inbound systems. UK HEIs, as claimed by Haywood et al. (2007), involve three customer interaction levels: operational, which manages customer accounts and contacts; tactical, to notify service enhancement and delivery; and strategic to inform better strategic decisions at the institutional level. Haywood et al. (2007) found that UK HEIs are willing to expand their CRM implementations, i.e. moving towards strategic, however very few UK HEIs have decided to deploy strategic systems (Haywood et al. 2007). Many UK universities that have made the decision to implement CRM still focus largely at the operational level.

While Grant and Anderson (2002) introduced different CRM systems' definitions in the academic area based on a range of HEI customers' viewpoints (student, staff and university management), Chambers and Paull (2008) found that these systems in UK universities are not strategically integrated, and are instead made up of separate sub-systems, each dealing with processes, decision-makers, information streams relating to its particular purpose. Accordingly, Biczysko (2010) proposed key changes that must be considered for HEIs to 
benefit from CRM systems implementation including mainly a focus on comprehensive integration of processes and gathered information across the whole university.

Although CRM solutions are widely adopted in the business world, and reports on CRM solutions use are normally available in literature (Nair et al. 2007), only a limited number of studies discuss CRM use in HEIs (e.g. Bagheri and Beheshti 2010, Biczysko 2010, Daradoumis et al. 2010, Grant and Anderson 2002), there is limited research considering how CRM should be strategically implemented within HEIs (Daradoumis et al. 2010, Hemsley-Brown and Oplatka 2006), and the research that does exist is generic in nature (e.g. Grant and Anderson 2002), and does not provide in-depth frameworks of how CRM strategy can be practically oriented and applied to maximise benefit in HEIs.

The most useful basis for UK HEI CRM is the three-part JISC project, entitled Relationship Management Programme, which studied CRM implementation in UK HEIs. The first part considered BCE and focused on business process change. The second part looked at Student Lifecycle Relationship Management (SLRM) and focused on improving student experiences and how effectiveness and efficacy can be improved by placing the student at the centre of all processes. The third part was focused on alumni projects liaison with different university areas (www.jisc.ac.uk). However, limited specific analysis of the 27 specific cases (13 BCE, 7 SLRM and 7 alumni projects) was provided. In the same context, previous research fails to mention how stakeholder activity and requirements can be linked to CRM solution types, and no structured approach has been suggested for use within UK HEIs demonstrating how CRM strategy can be orientated to align with university strategies and customer needs.

\section{DSR Methodology of developing CRM framework}

In order to develop our proposed CRM framework, we iteratively adopt Design Science Research (DSR) methodology steps proposed by Vaishnavi and Kuechler (2004) (see Figure 1a). By considering generic CRM implementation frameworks, and by paying special attention to strategy orientation, we define a theoretical framework (Artefact 1 - Generic Theoretical Artefact). Evaluation of Artefact 1 is carried out by analysing HEI specific CRM implementation case studies and 10 semi-structured HEI-based interviews, i.e. to better understand the specific issues impacting CRM implementations in HEIs (Artefact 2 Theoretical HEI CRM strategy Orientation Framework). Artefact 2 is developed to support HEI domain specific CRM strategy orientation framework. Five HEI Information Systems experts evaluated Artefact 2, and relevant changes are made; thus, supporting formation of our final artefact (Artefact 3), the CRM-SOS framework (see Figure 1b for steps of developing CRM-SOS framework). Ethical approval was gained prior to conducting all interviews and focus groups. Participants were clearly provided information about the aim of the research objectives and notified that although the session would be documented, all responses would be analysed anonymously and kept secure. All relevant interviews' quotations are presented in the following sections. 


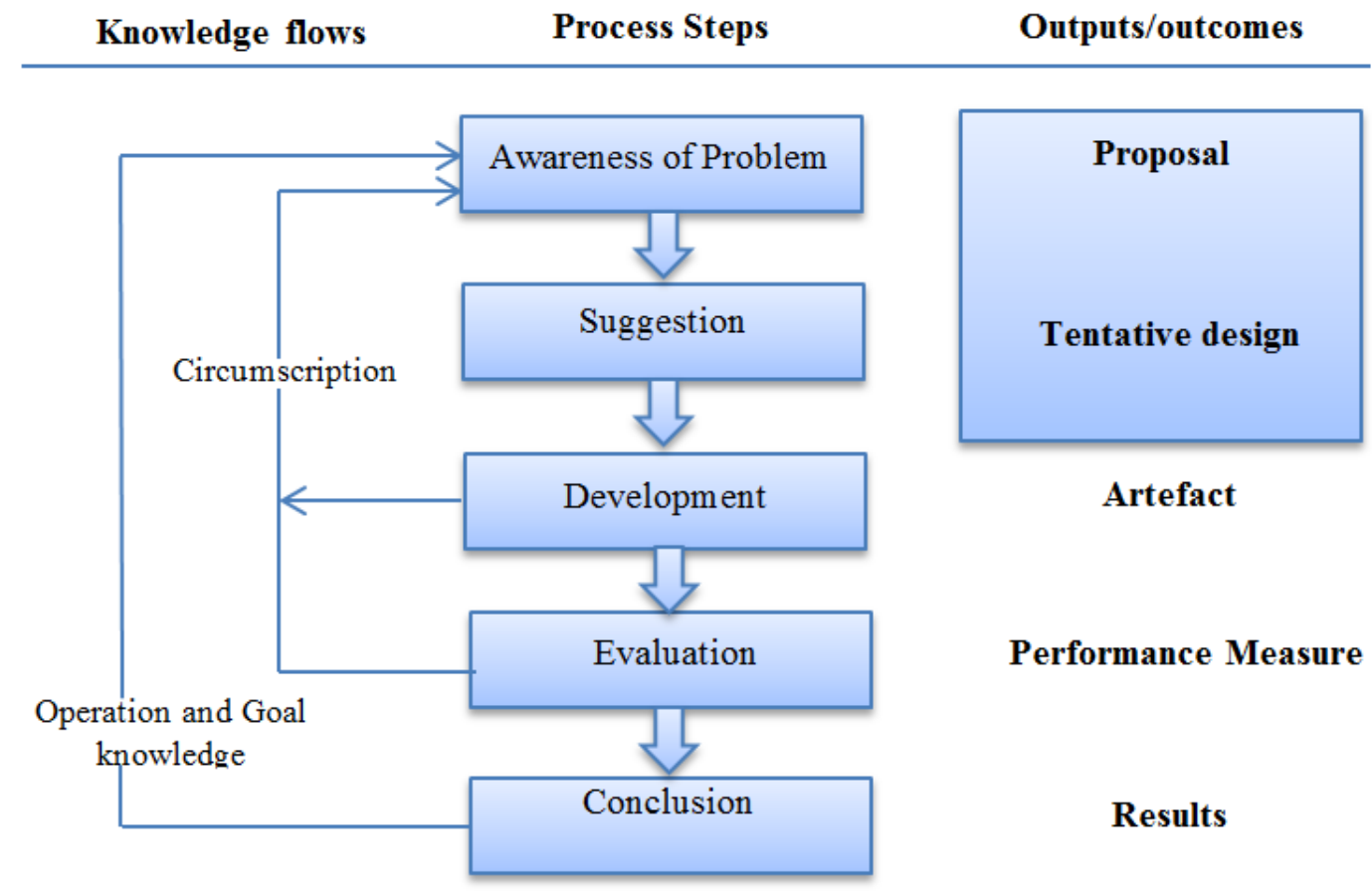

Figure 1a: DSR methodology, adopted from Vaishnavi and Kuechler (2004). 


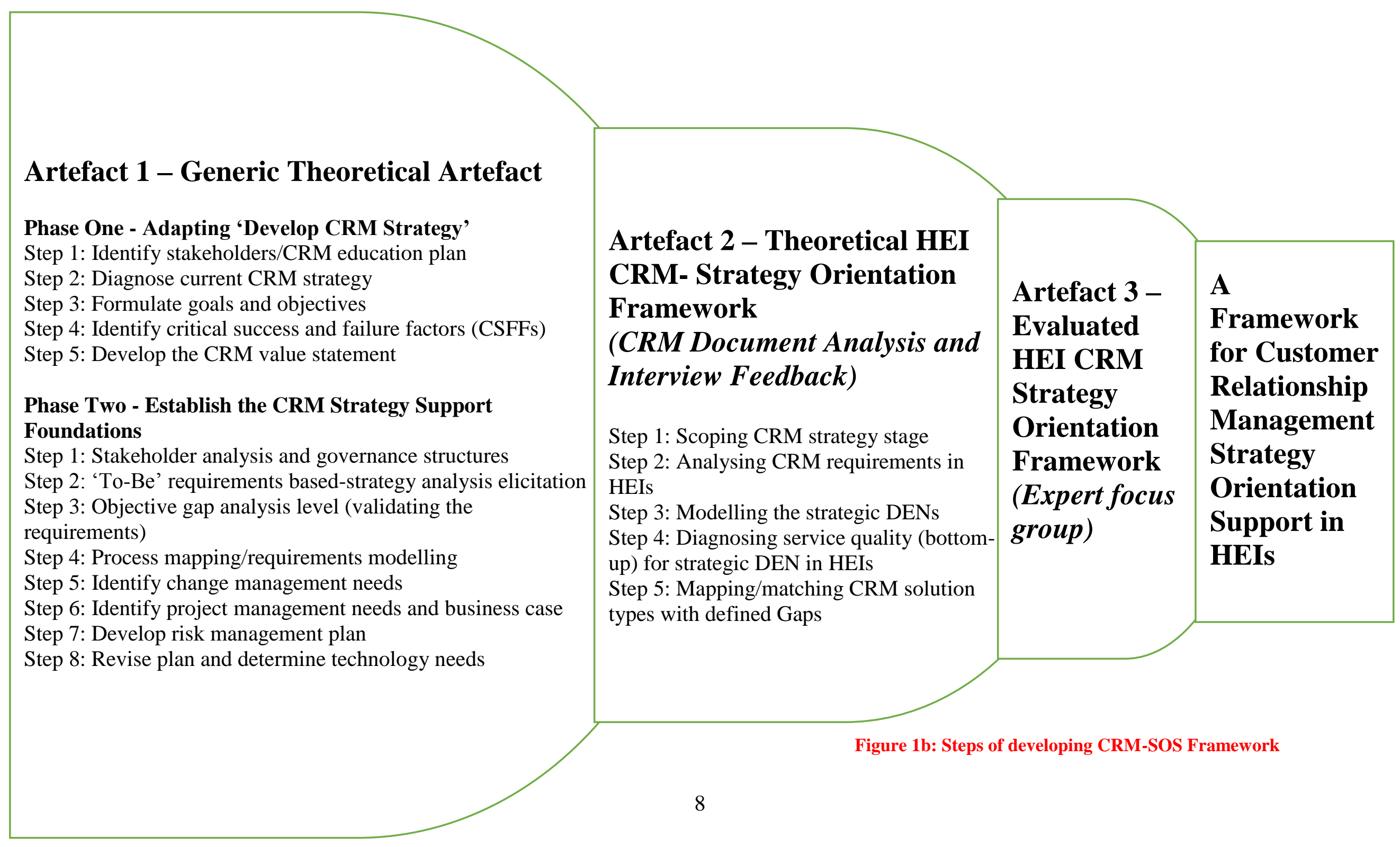




\section{Steps of developing CRM-SOS Framework}

\subsection{Artefact 1 - Generic Theoretical Artefact}

\section{Phase One - Adapting 'Develop CRM Strategy'}

Phase one within Buttle and Maklan original framework (Buttle and Maklan 2015), entitled 'Develop CRM Strategy', was reorganised, modified, and/or expanded. We chose their framework as a starting point in developing our framework as their model is the most relevant, recent and complete model that aims at minimizing errors and defining training needs; maximizing benefits for all stakeholders; and addressing a number of drawbacks raised in previous frameworks. The following sections describe the adapted steps in more detail (see Figure 2), providing justification for why each step has changed.

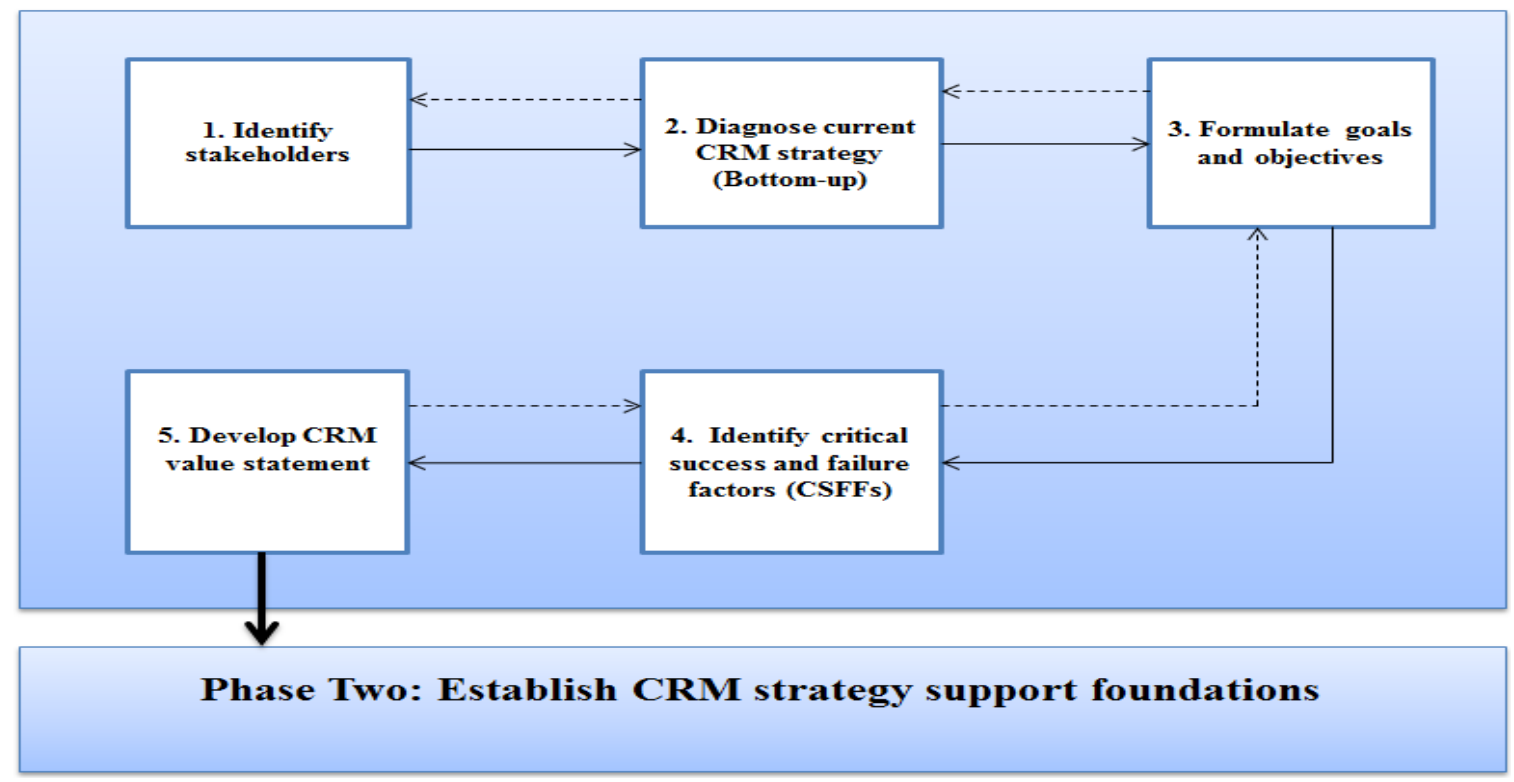

Figure 2: Phase One Adapting 'developCRM Strategy'.

\section{Phase 1, Step 1: Identify stakeholders/CRM education plan}

Buttle and Maklan (2015) did not consider stakeholder identification during phase one; accordingly, we added this step to explicitly define stakeholders; ensuring that leadership commitment and employee involvement can be sought at the project start. Stakeholder identification will help the organisation to identify those influencing, or influenced by, project outcomes. Once the CRM stakeholders have been identified, it is important that education and communication with stakeholders are prioritised to ensure CRM benefits are practically realised. CRM education is included as part of the first step, however, on-going education should be undertaken as required.

\section{Phase 1, Step 2: Diagnose current CRM strategy}

No CRM solution can be proposed unless the current activity and/or problems are properly understood. Situational analysis and requirements analysis is therefore important to CRM strategy definition (Chen and Popovich 2003). Performing situation analysis ensures that the organisation can make an informed decision concerning the CRM solution. Consequently, we include Buttle and Maklan step of "Set priorities" as step 2, i.e. named 'Diagnose current CRM Strategy'; allowing us to identify current CRM processes, people, technologies and channels, and assign gaps a specific CRM solution type (i.e. operational, analytical, strategic and collaborative). 
Phase 1, Step 3: Formulate goals and objectives

Greenberg (2010) stated that the pre-implementation phase is critically important, and that setting objectives is key for CRM strategy development. Our framework proposes that goals and objectives will emerge by applying situational and gap analysis, which allows us to define areas where value can be gained for key stakeholders. When all gaps have been prioritised, and allocated, CRM goals and objectives can be formulated defining what CRM solution types are required and where change should be focused.

Phase 1, Step 4: Identify critical success and failure factors (CSFFs)

Buttle and Maklan approach (2015) didn't support an awareness of critical failure factors, even though numerous researchers (Magana and Whitehead 2010, Almotairi 2010, and Thakur et al. 2006) highlighted this as being critically important. For each stated objective, and before defining change requirements, a step was added to allow us to understand limitations and assumptions before defining the CRM value statement.

\section{Phase 1, Step 5: Develop the CRM value statement}

Buttle and Maklan (2015) stated that senior management should define the CRM vision formed as a result of internal employee and customer's feedback. Accordingly, the 'Develop the vision' step in their original framework was moved to ensure that goals, objectives, and CSFFs were defined. In our work, separate value statements in terms of People, Process, Technology and Channels (PPTC dimensions) are grouped relating to CRM implementation solution type, i.e. operational, analytical, collaborative, and strategic. By dividing the vision into separate PPTC statements, we can be more specific concerning customers' needs, and therefore more specific when guiding achievable/desirable CRM implementation functionality.

\section{Phase Two - Establish the CRM Strategy Support Foundations}

Phase 2, Step 1: Stakeholder analysis and governance structures

Stakeholder identification is key in phase 2 step 1 to define critical/key stakeholders for each objective. During phase 2 step 1 we propose that the governance team should be defined, and should include key stakeholders (see Figure 3).

Phase 2, Step 2: 'To-Be' requirements based-strategy analysis elicitation People, process, technology and channel requirements, for each objective should be gathered to ensure key stakeholders are engaged in requirements identification and analysis.

Phase 2, Step 3: Objective gap analysis level (validating the requirements)

Gap analysis defines the difference between current activity, i.e. 'As-Is' (identified in Phase 1 Step 2), and intended activity, i.e. 'To-Be' (defined in Phase 2 Step 2). Gap analysis is positioned after requirements elicitation, as it is critical to know the requirements in order to facilitate identification of change management needs. 


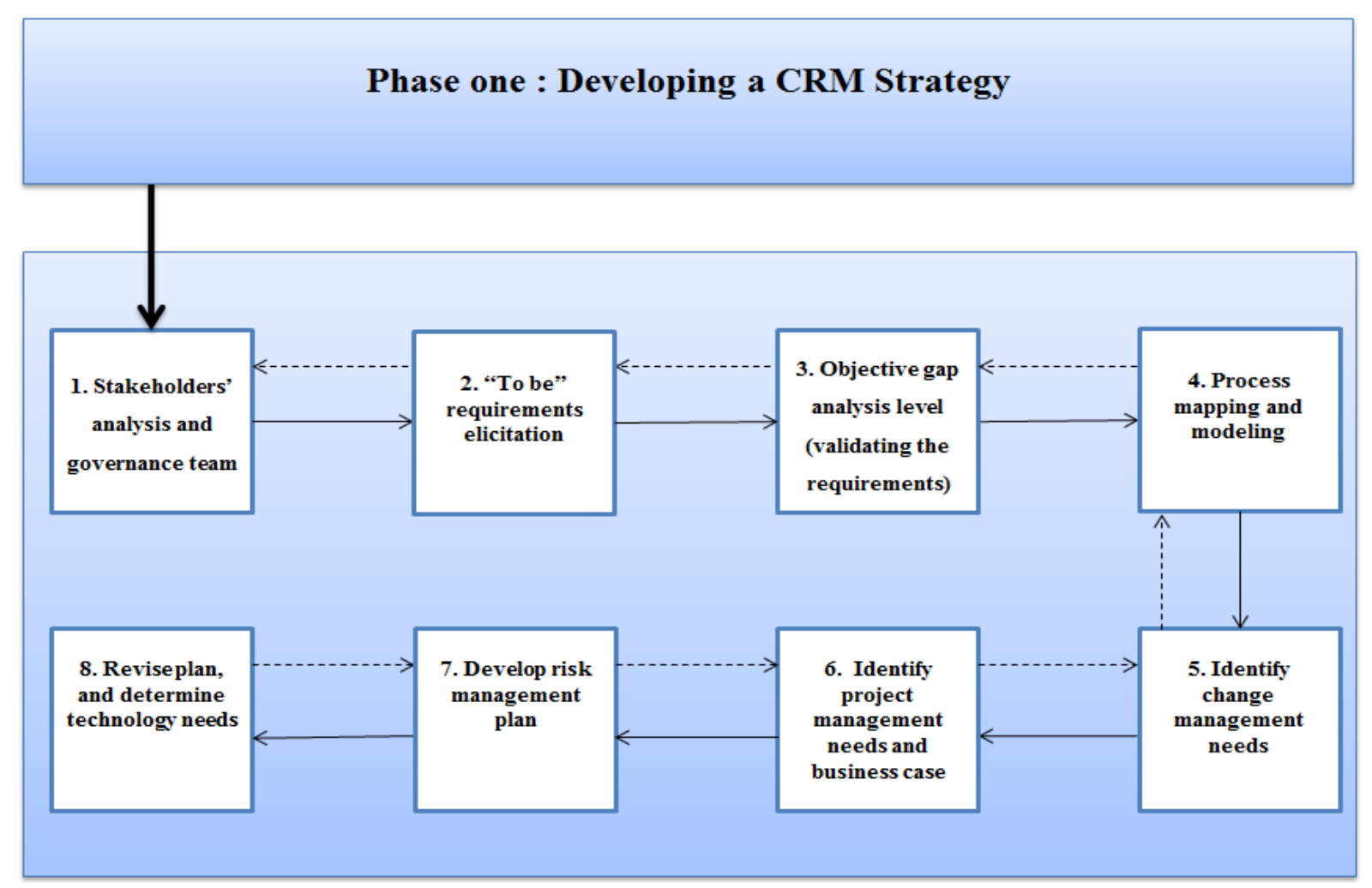

Figure 3: Phase two establishing the CRM strategy support foundations

Phase 2, Step 4: Process mapping/requirements modelling

In Buttle and Maklan (2015) framework, this step was the third step. We moved the 'Process mapping/requirements modelling' step to phase two in our framework. Modelling "To-Be" requirements help communication and increase stakeholder awareness concerning CRM goals.

Phase 2, Step 5: Identify change management needs

Once all the "As-Is" and "To-Be" requirements have been modelled, change management needs and capabilities are explicitly defined; allowing the definition of cost and resources.

Phase 2, Step 6: Identify project management needs and business case

'Identify people, process technology and channel requirements' and 'Develop the business case' steps, which are present in Buttle and Maklan (2015) original strategy phase, have been moved to phase two within our framework. All required changes should be translated into Key Performance Indicators (KPIs) to support the objective development of a business case.

Phase 2, Step 7: Develop risk management plan

The risk management plan reveals the importance of searching for alternative plans and scenarios in case of failure. To avoid metathesiophobia it is important to consider all change requirements in order that risks and/or alternative solutions can be identified.

Phase 2, Step 8: Revise plan and determine technology needs

This step aims to report all the final requirements, their change needs, their costs, and their benefits to senior management, all this information will also support the project team when selecting the CRM vendor selection. 
To gain a better understanding of UK HEI CRM activity and how artefact 1 needs to be adapted for use in HEIs, we approached stakeholders, identified in JISC documents and conducted semi-structured interviews. By tapping into the knowledge of the experience of implementers, we sought to gain an in-depth understanding of CRM implementation success and failure in HEIs.

\subsection{Artefact 2 - Theoretical HEI CRM- Strategy Orientation Framework CRM Document Analysis}

The JISC project studied 27 specific CRM implementation cases. To gain value concerning HEI CRM strategy orientation we analysed all JISC cases using thematic analysis. Thematic analysis highlighted a number of questions: Who should contribute to the design of 'To-Be' processes? How do we define missing process components? How should we map 'As-Is' and 'To-Be' processes? How should we manage change towards 'As-Is' daily activities? How can we link processes to the services provided by solution providers? In addition, analysis highlighted that process mapping is critical to CRM strategy orientation, and CRM strategy should be aligned with the university strategic goals in order to ensure management commitment. To support implementation JISC developed the Self-Analysis Framework (SAF), which was tested in twelve UK universities and one further education college. Thematic analysis feedback concerning SAF implied that SAF's lack of consideration concerning strategic planning, communication, modelling, and change management was of considerable concern; highlighting the need to consider these areas in our artefact development.

\section{Interview Feedback}

To gain a better understanding of HEI CRM activity we approached stakeholders identified in JISC documents including academics and practitioners. Purposeful sampling was used to ensure capture of information covering the main HEI CRM domains (i.e. students, business, and alumni). Ten semi-structured interviews were carried out with six different roles described in JISC case studies; including one vice chancellor (Participant 1), four project managers - two concerned with Business to Business (B2B) projects (Participants 2 and 3), one concerned with current student projects (Participant 4), and one concerned with marketing projects (Participant 5); two IT managers (Participants 6 and 7); and three CRM marketing mangers (Participants 8-10). Artefact one feedback was collected and thematically sorted. To guide artefact two the following themes were identified:

Define strategic leadership - 70\% of participants stated that top management should initiate CRM projects. To ensure management support, it is important to define strategic leadership. "It needs heads of department to push academics and administrators to use the system" (Participant 2). As involvement of senior stakeholders increases the chance of long-term CRM success, there is a need to identify senior people, at the pre-implementation stage, who are willing to help define and formulate CRM goals and visions. "The technology, the hardware, the software, is easy. It's the people that are the most important and the most complex part of implementing any large system over a large period of time. You're going to have conflicts with people, and between stakeholders, and it's the management of that which is pivotal to the success of any large project - especially a CRM system" (Participant 6).

Understanding the customer experience - Understanding customer needs/expectations allow CRM strategy to focus on areas that maximise value creation. Some participants, however, pointed out that "CRM strategy should not be based entirely on the student's needs, because 
there is no point in putting something in our strategy to say we will always respond within this amount of time if it's not physically possible" (Participant 3 ).

Lifecycle mapping - Considering processes, roles, events, activities, channels, and technology, in the context of customer lifecycle is important. Participants, however, highlighted that different customer groups need different solutions. "The undergraduate experience is very different to the PG experience" (Participant 5). It is important that the "As-Is' lifecycle of the focal customer group/domain is clearly defined. CRM solutions can help the university measure the customer experience at each lifecycle stage; to support evaluation and/or future development. Accordingly, it is essential to understand, and focus on, customer desires/expectations/needs to highlight service gaps.

Define CRM output - Participants highlighted a critical need to effectively scope the CRM implementation. $80 \%$ of participants mentioned that having a CRM strategy, at the preimplementation stage is essential; thus implying that CRM strategy should be clear before implementation. "For success, HEIs should use specific CRM systems to meet specifically defined needs" (Participant 1). Participants stated that understanding the required time, resources, effort, and change management limitations is critical to the definition of CRM implementation scope. Participants implied that small scope projects regularly result in fast, low risk, simple, and manageable outcomes and that large scope projects are more complex, costly and risky; yet are more impactful if managed successfully.

Define strategic stakeholder groups - One participant mentioned that managing people is the most important part of the implementation; as it improved project communication, strategic leadership, and conflict resolution. "People are the most important and the most complex part of implementing any large system" (Participant 6). 70\% of participants defined the need to have "sub-strategies for different sectors and customer groups", i.e. to allow guidance of activity in the context of different people groups (teaching, research, knowledge transfer etc.). If CRM sub-strategies are defined for specific HEI domains, it is important to define what stakeholders relate to specific sub-strategies.

Defining data owners - "The biggest problem was getting the right information into the system in the first place, because without data, and trust in data, you can't really do anything in CRM" (Participant 8). Accordingly, defining the data owners is essential to identify data sources and reduce the confusion of data migration.

Quantify customer needs $-90 \%$ of participants discussed the definition of CRM goals and objectives. When formulating goals it is important to quantify needs, e.g. cost of resources, the scope of the implementation, quality expectations, and time restrictions. A SMART criterion was a point raised by half of the participants as a good approach to manage CRM objectives. "If you have smart goals they become the guiding principles to work against" (Participant 2).

Rationalise project resources - Participants stated that, to obtain tangible and intangible benefits, there is a need to explicitly allocate adequate resources, i.e. funds, people, time. Appropriate consideration of human resources is key to resource consideration. "If there is a lack of skilled personnel, the university will need to outsource to a provider, and manage that relationship - that's very tough" (Participant 10). Another participant raised the point that it is sometimes difficult to determine the required resources at the beginning of the project; 
emphasising the need to carefully scope the implementation. "I don't think from the outset people know what is really involved and how much resources the project will need" (Participant 8). Although seemingly paradoxical, i.e. there is a need to ensure allocation of resources yet no explicit resource allocation is clear; again, emphasising a need to explicitly scope the implementation.

Selecting CRM solution vendor - Participants highlighted the need to define CRM needs before selecting a CRM provider. Half of the participants discussed the importance of taking care when selecting the CRM provider, with many suggesting that limitations in solution functionality compromised project success. "It's about being very careful about who you select" (Participant 8), i.e. ensuring you understand the market options and only select the CRM solution after extensive research. Definition of the implementation goals, objectives, stakeholders, and CRM system requirements, in advance of CRM provider selection, is critical to determine whether a CRM provider can satisfy the specific HEI needs.

\section{Developing Artefact 2}

Document analysis and practitioner interviews confirmed the need to keep all steps from artefact one. To support the inclusion of additional considerations, however, the grouping and positioning of stages are needed to be changed for application in HEIs (see Figure 4).

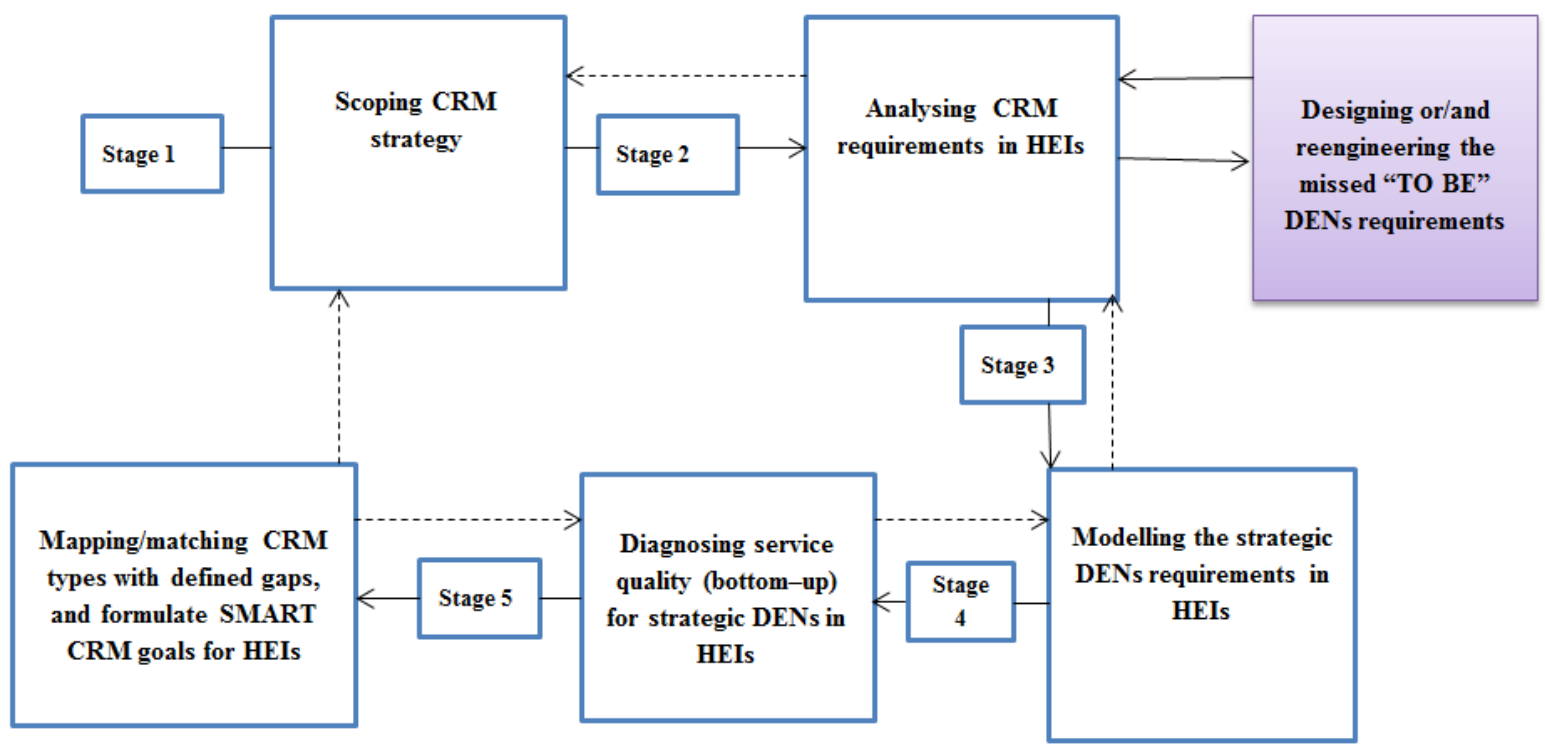

Figure 4: Artefact 2 - HEIs CRM strategy orientation framework

\section{Artefact 2, Step 1: Scoping CRM strategy stage}

One of the key factors was the scoping of CRM strategy. Since the artefact 1 did not consider scoping of strategy, this is explicitly added to artefact 2 entitled "Scoping CRM strategy". This stage is critical for HEIs due to the diversity in the outputs and focus within HEIs (i.e. teaching, knowledge transfer, etc.), which drives a need for flexibility in the scoping approach; to ensure that top management initiate the CRM strategy and management and customer desires/expectations/needs are considered; to decompose HEI outputs, since different domains require service delivery for different beneficiary recipients (e.g. prospective, student, businesses, academic staff, alumni etc.); artefact 2 interview participants supported the idea of defining smaller domain specific CRM focused solutions, i.e. to simplify implementation and maximise the benefit gained from allocation of resources; as there is limited consideration of 
methods to help identify and analyse the stakeholders, i.e. to help define the people who will have an interactive relationship with, and manage, the customer experience; due to the increasing trend towards customer-centricity in HEIs, i.e. to dynamically appreciate customer needs/expectations requirements, and adapt university activities around these requirements; as there is an increasing focus placed on the importance of the customer experience as a critical element for university strategy and assessment, e.g. national student survey impacting HEI ranking.

Scoping aims to define the focal problem output, thus ensuring the CRM implementation focuses on areas perceived to be 'of importance'; define and analyse stakeholders involved in the specific domain/output, in order to understand the scope of influence; segment customers into semantically relevant groups, identifying strategically important clients; define the stakeholder's Desires/Expectations/Needs (DEN); minimise risk, scope shift, and maximise change management (Chen and Popovich 2003) enabling iterative, manageable and focused CRM implementation; align the DENs from stakeholders are and to agree on strategic ones.

\section{Artefact 2, Step 2: Analysing CRM requirements in HEIs}

$60 \%$ of the interviews highlighted the importance of mapping 'As-Is' and 'To-Be' processes to understand whether current Processes, Roles, Events- Activities, Communications, Technology (PRE-ACT) components are satisfactory. To map 'As-Is' and 'To-Be' CRM requirements, analysing CRM requirements in HEIs stage was added to our framework to map the client DEN in the current "As-Is" and map this onto the "To-Be" methods; identify any missing requirements, i.e. DEN that cannot be effectively mapped onto "To-Be" CRM components; check whether the university can already meet the missing requirements internally, i.e. services provided elsewhere that would meet DEN. If the university cannot meet these DENs, then change is needed to facilitate the creation of the new services.

\section{Artefact 2, Step 3: Modelling the strategic DENs}

Document analysis highlighted a need to model strategy components (PRE-ACT); hence an explicit stage entitled "DENs requirements modelling" was added to artefact 2.

\section{Artefact 2, Step 4: Diagnosing service quality (bottom-up) for strategic DEN in HEIs}

The 'Diagnosing service quality' stage evolved from the stage 2, phase 1, i.e. 'Diagnose current CRM strategy'. Evidence from both the document analysis and interview data suggested that there is a need to understand the perspective of strategic clients. Document analysis highlighted a need to add a 'feedback from clients' stage. Interview participants also defined a need to take into account the client's perspectives when developing CRM strategy. If services are not gaining positive feedback, then redesign of services is required. Iteration should continue until positive feedback is gained.

\section{Artefact 2, Step 5: Mapping/matching CRM solution types with defined Gaps}

$60 \%$ of participants suggested using SMART criteria when developing HEI CRM objectives. SMART KPIs should be linked to CRM goals and CRM implementation solution types to facilitate measurement of implementation success. Once strategic DENs are aligned, we can link the university requirements with the most suitable technological solutions, which facilitate satisfaction of CRM value statements. 


\subsection{Artefact 3 - Evaluated HEI CRM Strategy Orientation Framework}

To evaluate artefact 2, and facilitate the development of artefact 3, we conducted an expert focus group. Five practitioner participants were included in the expert focus group. Purposeful and convenience sampling was used to capture relevant information. Experts included: a usability and enterprise architecture consultant/researcher (Participant A); an academic with extensive knowledge in enterprise systems and human computing (Participant B); a researcher with extensive knowledge of MIS, e-commerce, and technology acceptance (Participant C); a researcher with experience in business processes and MIS (Participant D); a consultant with extensive knowledge in process mapping and modelling (Participant E). All experts had extensive experience of HEIs and IS implementation. Feedback from experts is presented below:

Artefact 3, Step 1 - All participants understood the reasoning behind scoping, and agreed its significance as the first stage. Participants questioned how strategic clients were defined and prioritised, and suggested that additional information is needed to support understanding the difference between desires, expectations and needs. "It would be good if you integrate the steps with examples" (Participant B).

Artefact 3, Step 2 - The lifecycle approach was appreciated by participants. "This consideration will help the HEI define a lifecycle for clients" (Participant A). Participants liked the idea of mapping CRM requirements and "To-Be" processes, i.e. "to ensure all requirements are met" (Participant E). Although the participants liked the idea of mapping the CRM requirements to "To-Be", i.e. to ensure all requirements are met, they suggest having "Identity Documents (IDs) and different versions of the life cycles" (Participant E).

Artefact 3, Step 3 - All participants stated that Unified Modelling Language (UML) and Business Process Model and Notation (BPMN) are insufficient to link strategic goals and operational activity. IS experts suggested the use of ArchiMate. "ArchiMate has strategic and operational elements that would allow you to link strategic (business), operational (application), and technical levels" (Participant A). Caution was raised, however, that contextual justification must be considered. "You don't want to say 'use ArchiMate', as it may change" (Participant C).

Artefact 3, Step 4 - Whilst all IS experts supported measurement of service quality; they asked how service quality would be measured. "How does that relate to CRM quality and activities?" (Participant B). Experts stated that "CRM is about how customers perceive their experience of the service" (Participant B).

Artefact 3, Step 5 - Participants found the fifth stage very useful in terms of formulating SMART CRM goals; i.e. linking measurable KPIs, and connecting needs to one or more CRM types. Participants, however, mention the need to "prioritise the solutions" (Participant C). "Universities only have a certain amount of money, and can't buy everything they need" (Participant A). Participants identified that "you will never find a perfect solution". In that vein, participant 4 recommended "ordering the gaps", i.e. weighting them based on the strategic DENs and/or business KPI. In addition, expert participants suggested adding return paths to stages 1, 2 and 4, i.e. in case of problems need to be resolved (see Figure 5). 


\section{Developing Artefact 3}

Expert feedback provided insightful evaluation points, which were used to guide artefact 3 developments (see Figure 5). As a result of feedback, the final CRM-SOS framework is able to connect strategic HEIs drivers to the low-level requirements through actionable sub-steps. Figure 5 presents the framework with a flow following the solid arrows. The first stage scopes and aligns the CRM strategy with the university strategy and customer DENs. The outcome is the aligned and agreed on DEN list. The second step analyses DENs requirements (PRE-ACT) to map requirements within the client interaction lifecycle. The outcome of this stage defines any new or missed PRE-ACT that need to be designed. The third step models DEN using an appropriate modelling language. The fourth stage measures the quality of the "To-Be" DENs requirements to identify DEN requirement quality gaps. The final stage prioritises gaps by considering CRM types, in order to formulate SMART CRM goals, develop risk management plans, and assess the system performance. The inclusion of high-level iteration facilitates flexibility, personalisation of stages, and quality tracking of changes. For example, the framework is designed for use by universities that want to launch CRM implementations, however, the framework could be personalised to support HEIs that have already implemented CRM solutions in their university; especially to help diagnose their current CRM strategy situation starting from the second stage. The framework can be used to personalise the stages until they fit the strategic outputs and match the top management KPIs, while tracking any change that might influence the steps, flow, or content.

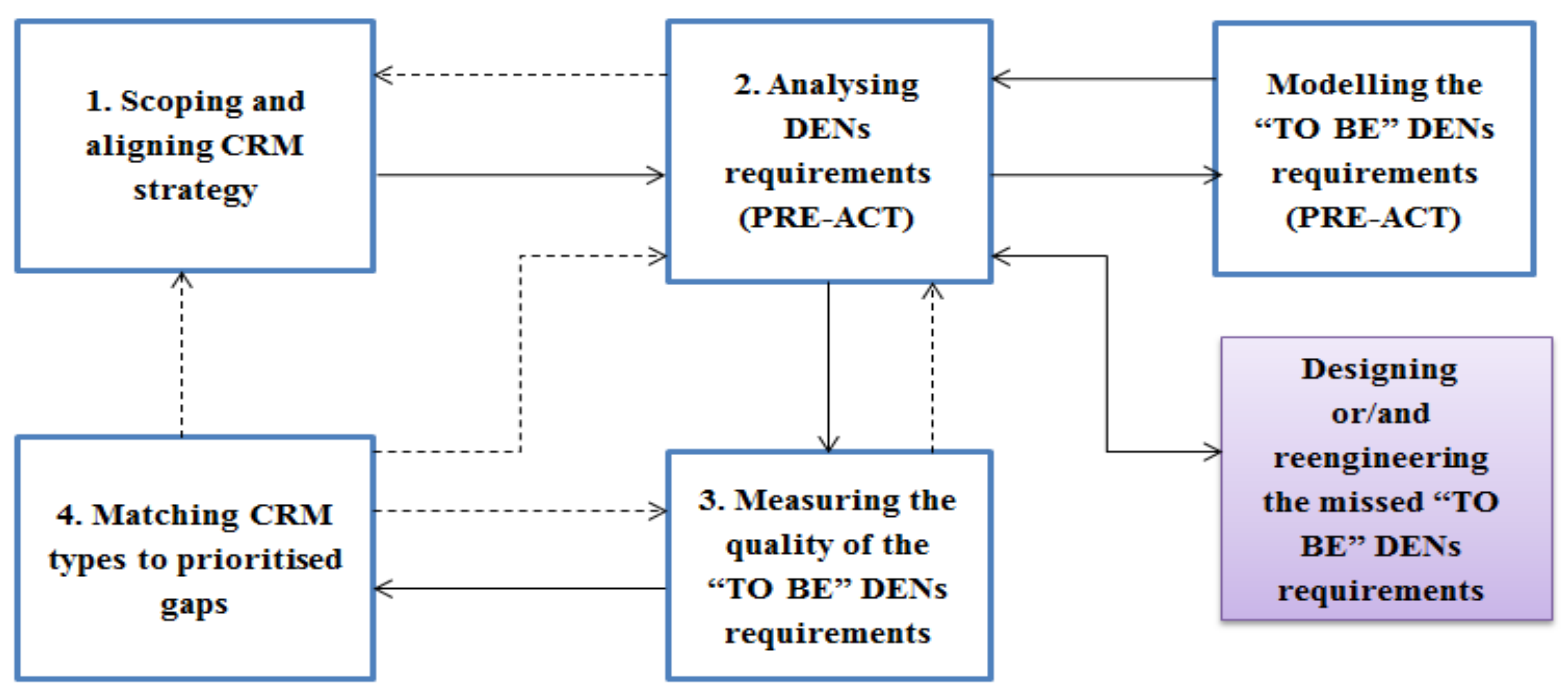

$(D E N s)=$ Desires, Expectation and Needs

$($ PRE-ACT) $=$ Processes, Roles (people), Events, Activities, Communication Channels and Technology

Figure 5: Artefact 3 HEI CRM Strategy Orientation Support framework; including iteration and optional modelling flow

\section{Conclusion}

HEI managers should be involved in the CRM project implementation, especially at the preimplementation stage, when buy-in and coordination are significant. Strategic CRM in HEIs should be planned and implemented in focused areas. If scoped implementation is successful, then the solution can be expanded; taking into account local strategic desires, expectations, and 
needs. The CRM-SOS framework should be used by the internal analyst/project-manager with some help, as appropriate, from external consultants.

Although generic CRM implementation frameworks have been defined, we highlighted a need for a HEI specific framework to support pre-implementation CRM strategy orientation. In this paper, using design science as a method, we iteratively develop the CRM Strategy Orientation Support (CRM-SOS) framework for use strategically and practically by HEIs. Artefact 1 combined and incorporated theoretical factors that influence CRM strategy orientation; facilitating the generation of a generic CRM strategy orientation framework. Evaluation of artefact 1, using document analysis and semi-structured interviews, helped define HEI specific requirements; supporting the development of artefact 2 which was evaluated by practitioner focus groups. Specialists defined artefact stages as logical in the context of a practical IS implementation. As a result of expert feedback, artefact 3 was developed for use by HEIs .

HEIs are complex organisations, and although additional work is required to consider relevant implementation methods, for use with segmented HEI customers, the proposed CRM-SOS framework offers considerable practical pre-implementation support to help implementers avoid CRM failure in HEIs, whilst maximising the strategic value return for both HEIs and customers. To the best of our knowledge, no previous study has examined these concepts/flows using multiple evaluations, nor have previous frameworks highlighting the importance of practical implementation methods/techniques for use strategically in HEIs.

\section{References}

Almotairi, M. (2010). Evaluation of the Implementation of CRM in Developing Countries. $\mathrm{PhD}$ thesis, University of Brunel.

Bagheri, A. and Beheshti, M. (2010). Exploitation of CRM for Strategic Marketing in Higher Education: Creating a Knowledge-based CRM Framework for Swedish Universities .Master Thesis, Jönköping University.

Biczysko, D. (2010). CRM solutions for Education. In: Jałowiecki, P., and Orłowski, A. ed. 2010. Information Systems in Management, Distant Learning and Web Solutions for Education and Business. WULS Press, Warsaw, 1st edition: 18-29.

Binsardi, A. and Ekwulugo, F. (2003). International marketing of British education: research on the students' perception and the UK market penetration. Marketing Intelligence \& Planning, 21(5): 318-327.

Bligh, P. and Turk, D. (2004). CRM Unplugged Releasing CRM's Strategic Value. John Wiley \& Sons, Inc.

Buttle, F. and Maklan, S.(2015). Customer Relationship Management: Concepts and Technologies. Routledge.

Cambra-Fierro, J.J. Centeno, E. Olavarria, A. and Vazquez-Carrasco, R. (2017). Success factors in a CRM strategy: technology is not all. Journal of Strategic Marketing, 25(4): 316333. 
Coltman, T. (2007). Why build a customer relationship management capability?. The Journal of Strategic Information Systems. 16(3): 301-320.

Chambers, D. and Paull, A. (2008). Landscape Study of Student Lifecycle Relationship Management, JISC report. Available from: http://www.jisc.ac.uk/media/documents/programmes/jos/slrm_report.pdf. [Accessed 2nd June 2012].

Chen, I. J. and Popovich, K. (2003). Understanding customer relationship management (CRM) People, process and technology. Business Process Management Journal. 9(5): 672-688.

Daradoumis, T. Rodríguez-Ardura, I. Tibidabo, Faulin, J. Juan, A. Xhafa, F. and MartínezLópez, F. (2010). CRM applied to higher education: developing an e-monitoring system to improve relationships in e-learning environments. International Journal of Services Technology and Management. 14 (1): 103-125.

Grant, G. and Anderson, G. (2002). Customer relationship management: a vision for higher education. In: Katz, R. (Ed.). Web Portals and Higher Education: Technologies to Make IT Personal. John Wiley \& Sons, Inc., New York: 23-32.

Green, D. (1994). What is quality in higher education? Concepts, policy and practice. In Green, D. (Ed.), 1994, What is Quality in Higher Education?, Buckingham, Open University Press and Society for Research into Higher Education: 3-20.

Greenberg, P. (2010). CRM at the Speed of Light: Social CRM Strategies, Tools, and Techniques for Engaging Your Customers. Fourth Ed, the McGraw-Hill Companies.

Gummesson, E. (2009). Total Relationship Marketing. 2nd ed, Oxford, ButterworthHeinemann.

Kaiser, F. Meer, P. Beverwijk, J. Klemperer, A. Steunenberg, B. and Wageningen, B. (1999). Market type mechanisms in higher education / a comparative analysis of their occurrence and discussions on the issue in five higher education systems. Thematic report. VI: 12-37.

Kirkby, J. (2002). Developing a CRM Vision and Strategy. (A1, CRM31). Gartner group. CRM Summit: Moving from Disillusionment to Real Value. Hotel Sofitel Paris Forum Rive Gauche 22-23 May. Available from: http://www.mycustomer.com/files/siftmediamycustomer/gartner-005.pdf. [Accessed 2nd Oct 2014].

Kotler, P. and Fox, K. F. (1985). Strategic Marketing for Educational Institutions. PrenticeHall.

Kumar, M. (2010). Impact of CRM in mechanizing university's process, business and productivity. Global Journal of Enterprise Information System. 2 (2): 43-48.

Lávanya, T. (2011). Customer relationship management and higher education -a vision. Advances in Management. 4 (3): 18-20. 
Lagrosen, S. Seyyed-Hashemi, R. and Leitner, M. (2004). Examination of the dimensions of quality in higher education. Quality Assurance in Education. 12(2): 61-69.

Leigh, T. W. and Tanner, J. F. (2004). Introduction: JPSSM special issue on customer relationship management. Journal of Personal Selling and Sales Management. 24(4): 259-262.

Lindgreen, A. Palmerb, R. Vanhammec, J. and Wouters, J. (2006). A relationship management assessment tool: Questioning, identifying, and prioritizing critical aspects of customer relationships. Industrial Marketing Management. 35 (1): 57-71.

Harvey, L. and Knight, P. T. (1996). Transforming Higher Education, ERIC.

Hanover Research. (2010). Customer Satisfaction Measures- Academy Administration Practice. Available from: http://www.planning.salford.ac.uk/_data/assets/pdf_file/0005/20669/Customer-SatisfactionMeasures-Membership.pdf. [Accessed 23 Oct 2014].

Haywood, M. Nixon, I. Bowden, A. and Bell, R. (2007). Study of Customer Relationship Management (CRM) Issues in UK Higher Education Institutions. JISC reports . Available from: http://www.jisc.ac.uk/media/documents/themes/bce/crmstudyfinalreport20070817.pd. [Accessed 3rd Nov 2012].

Hemsley-Brown, J. and Oplatka, I. (2006). Universities in a competitive global marketplace: A systematic review of the literature on higher education marketing. International Journal of Public Sector Management. 19 (4): 316-338.

Magana, A. and Whitehead, M. (2010). Implementing Sugar CRM: 5.x.Install, Configure, and Administer a Robust Customer Relationship Management System Using SugarCRM. Packt, p12.

Mattheou, D. and Saiti, A. (2005). The organisation of academic work and university administration: a qualitative study from Greece. Conference on Trends in the Management of Human Resources in Higher Education. Available from: http://www.oecd.org/edu/imhe/35327298.pdf. [Accesed 2nd Jan 2012].

Mellors-Bourne, R. Metcalfe, J. Pearce, E. and Hooley, T. (2014). Understanding the Recruitment and Selection of Postgraduate Researchers by English Higher Education Institutions. Report to HEFCE by CRAC/Vitae and iCeGS. Available from http://dera.ioe.ac.uk/20948/1/2014_pgrrecruitment.pdf Accessed 5th November 2014].

Nair, C. Chan, S. and Fang, X. (2007). Adoption of CRM in Higher Education. IRMA International Conference: 221-224.

Neville, K. Adam, F. and McCormack, C. (2002). Mentoring distance learners: an action research study. ECIS. Proceedings Conference: 1410-1421. 
O'Regan, S. (2010). CRM for Future Skills in Creative Industries in West London: Overview of the Self-Analysis Framework. [Online]. Available at: http://wiki.cetis.ac.uk/images/2/24/RoehamptonCaseStudyandAppendices.pdf. [Accessed: 8th November 2013].

Payne, A. (2005). Handbook of CRM: Achieving Excellence in Customer Management. Butterworth-Heinemann: 23-24.

Payne, A. and Frow, P. (2005). A strategic framework for customer relationship management. Journal of Marketing. 69(4): 167-176.

Peppers, D. and Rogers, M. (2004). Managing customer relationships: A strategic framework. John Wiley \& Sons.

Perry, S. Corley, L. and Hollins, P. (2011). Relationship Management in UK Higher and Further Education - An Overview. [Online]Available at http://wiki.cetis.ac.uk/images/a/a2/JISC_CETIS_RMSAS_Project_RM_Programme_Phase_1 _Synthesis.pdf. [Accessed 11th November 2013].

Rigo, G.E. Pedron, C.D. Caldeira, M. and Araújo, C.D. (2016). CRM adoption in a higher education institution. JISTEM-Journal of Information Systems and Technology Management. 13(1): 45-60.

Rigby. D. and Ledingham, D. (2004). CRM done right. Harvard Business Review. November: p.11.

Saitia, A. and Prokopiadou, G. (2008). Post-graduate students and learning environments: Users' perceptions regarding the choice of information sources. The International Information \& Library Review. 40 (2): 94-103.

Seeman, D.E. and O'Hara, M. (2006). Customer relationship management in higher education: Using information systems to improve the student-school relationship. Campus - Wide Information Systems. 23 (1): 24-34.

Seligman, J. and Taylor, J. (2009). Customer Experience Management in UK Higher Education a Mixed Methods Study. ANZMAC, Melbourne.Available from: http://www.duplication.net.au/ANZMAC09/papers/ANZMAC2009-405.pdf. [Accessed 4th Jan 2013].

Thakur, R. Summey, J.H. and Balasubramanian, S. K. (2006). CRM as strategy: avoiding the pitfall of tactics. Marketing Management Journal. 16 (2): 147-154.

Vaishnavi, V. and Kuechler, B. (2004). Design Research in Information Systems. AIS: January 20.

Wali, A.F. and Wright, L.T. (2016). Customer relationship management and service quality: Influences in higher education. Journal of Customer Behavior. 15(1): 67-79. 
Wali, A. F. Wright, L. T. Nwokah, N. G. and Reynolds, P. (2015). Customer relationship management and service quality: a qualitative study. EURAM 2015 (European Academy of Management) Conference. Available from: http://eprints.hud.ac.uk/25053/1/1145Customer_Relationship_Management_and_Service_Qu ality_Performance_a_qualitative_study.pdf. [Accessed 5th November 2013], pp.1-20. 